\title{
The effect of surgical treatment on secondary hyperaldosteronism and relative hyperinsulinemia in primary hyperparathyroidism
}

\author{
László Kovács, Miklós I Góth, István Szabolcs, Orsolya Dohán, Antal Ferencz ${ }^{1}$ and Géza Szilágyi \\ 1st Department of Internal Medicine, Division of Endocrinology and ${ }^{1}$ Laboratory Institute, Haynal Imre University of Health Sciences, \\ Budapest, Hungary
}

(Correspondence should be addressed to László Kovács, 1st Department of Internal Medicine, Division of Endocrinology, Haynal Imre University of Health Sciences, H-1135 Budapest, Szabolcs u. 35, Hungary)

\begin{abstract}
Objective: To evaluate the renin-aldosterone system and insulin secretion in hyperparathyroidism and their effects on blood pressure regulation.

Design: Studies were carried out on patients with primary hyperparathyroidism (PHPT) prior to and following removal of the parathyroid tumor.

Methods: Sixteen normotensive and euglycemic patients with PHPT were studied. The following parameters were measured: basal and stimulated plasma renin activity (PRA) and aldosterone (ALD) secretion; parathormone (PTH) and serum electrolytes. Insulin and glucose levels were measured during an oral glucose tolerance test.

Results: Systolic but not diastolic blood pressure showed a decrease following surgery, from $123.3 \pm 13.0 / 80 \pm 8.6$ to $116.7 \pm 13.5 / 77.3 \pm 8.8 \mathrm{mmHg}$. The decrease in the systolic pressure was not clinically significant. After surgery, both the basal and stimulated PRA and ALD values decreased, and the preoperative pathological values returned to normal: PRA basal: $1.79 \rightarrow 0.70 \mathrm{ng} / \mathrm{ml} / \mathrm{h}, P=0.0049$; PRA stimulated: $7.76 \rightarrow 1.90 \mathrm{ng} / \mathrm{ml} / \mathrm{h}, P=0.0031$; ALD basal: $111.5 \rightarrow 73.0 \mathrm{pg} / \mathrm{ml}, P=0.0258$; ALD stimulated: $392.5 \rightarrow 236.0 \mathrm{pg} / \mathrm{ml}, P=0.0157$. The postoperative decrease in the PRA correlated with the changes in PTH levels $(r=0.5442, P<0.05, n=16)$ but did not correlate with the changes in serum calcium concentrations. Both the fasting and stimulated insulin levels decreased after surgery but remained within the normal range: insulin fasting: $10.2 \rightarrow 5.0 \mathrm{mIU} / \mathrm{l}, P=0.0218$; insulin area under the curve: $5555 \rightarrow 3296 \mathrm{mIU} / \mathrm{l}^{*} \mathrm{~min}, P=0.0218$. There was no correlation between the changes in insulin levels and PTH or ion levels. Sodium, potassium and blood glucose levels remained unaffected by parathyroid surgery.

Conclusions: In a population of normotensive hyperparathyroid patients an increased activity of the renin-aldosterone system related to PTH was found and surgery resulted in a small and insignificant decrease in blood pressure. This change was accompanied by a significant decrease in the activity of the renin-aldosterone system indicating the role of the renin-aldosterone system in the regulation of blood pressure in PHPT. Both fasting and stimulated insulin values decreased following removal of the parathyroid tumor, but with no individual correlation with PTH and calcium levels.
\end{abstract}

European Journal of Endocrinology 138 543-547

\section{Introduction}

Primary hyperparathyroidism (PHPT) is frequently accompanied by hypertension, but the reasons for this remain unclear. It is well known from experiments that parathormone (PTH) may directly stimulate renin release in the myoepithelial cells of the preglomerular arterioles and that the inhibition of calcium influx plays a crucial role in this (1). However, clinical examination of the plasma renin activity (PRA) and aldosterone secretion (ALD) in PHPT resulted in contradictory data, i.e. some investigators found no change in the basal values of PRA and ALD (2-5) and in the responses given to angiotensin II stimulation (6), while others measured increased values which reverted to normal following parathyroidectomy (7-9). No data were found in the literature regarding the changes in PRA during a stimulation test by volume depletion and orthostasis in PHPT patients.

A pathogenic link between arterial hypertension and insulin resistance, hyperinsulinemia, has also been generally accepted and widely studied (for reviews see (10-12)). In PHPT patients, the incidence and prevalence of impaired glucose tolerance and diabetes 
mellitus is significantly increased compared with the normal population $(13,14)$. Several authors have described hyperinsulinemia or insulin resistance in PHPT (15-17). At the same time, however, some authors did not see any change in the basal and stimulated insulin levels following parathyroidectomy $(15,17)$, while others observed a significant reduction $(13,18)$.

Our clinical study on the regulation of blood pressure in PHPT differs from the previous reports in various aspects: (i) both the basal and stimulated PRA and ALD levels were measured in PHPT prior to and following surgery; (ii) a more complex approach was used for investigating simultaneously both the renin-aldosterone system and insulin secretion in PHPT and correlating their changes to the changes in the PTH and electrolyte levels; (iii) only normotensive and euglycemic patients with PHPT were selected for the study, based on the understanding that the hormonal changes after parathyroidectomy would be more reliable in a homogenous group rather than in consecutive PHPT patients with or without hypertension or diabetes mellitus.

\section{Subjects and methods}

Sixteen patients with PHPT (13 females, 3 males; their ages ranging from 16 to 66 years, mean age 49 years) were selected for the study. Written informed consent was obtained from each patient. Parathyroid tumor was confirmed by histological examination in all cases, 3 of them being malignant, and 13 being benign. All the patients had a single tumor, all of them were operated on in the same way and there was no difference in the clinical time course of the disease regarding the histological findings. The patients were free from any other endocrine diseases and they did not have diabetes mellitus or impaired glucose tolerance or hypertension. On the basis of body mass index, only one patient was obese. During the study period the patients were not given any preparations affecting calcium metabolism, PRA, ALD, blood glucose or insulin values; otherwise they received their usual medication. In case of need, calcium was administered following removal of the parathyroid tumor.

The following parameters were measured after $8 \mathrm{~h}$ of strict bed rest at $0700 \mathrm{~h}$ in the preoperative period and 7 days after the surgery: basal PRA and ALD, serum sodium (seNa), potassium (seK), calcium (seCa), magnesium (seMg), phosphorus (seP), and PTH. After $40 \mathrm{mg}$ furosemide i.v. and 4-h orthostasis, blood was withdrawn to determine the stimulated plasma renin activity and aldosterone concentration. In 12 out of the 16 patients, prior to and 8 days after surgery the glucose and insulin concentrations were determined during an oral glucose tolerance test (OGTT) with $75 \mathrm{~g}$ glucose at 0, 30, 60 and $120 \mathrm{~min}$. The magnitudes of the glucose and insulin responses are expressed by the area under the curve (AUC). The curve was constructed by delineating the values measured at various time points. Trapezoid method was used for the calculation: the sum of the areas determined by the corresponding values of the $y$ axis (concentrations) and $x$ axis (time points) was calculated. Blood pressure changes were also noted. Blood pressure was measured in a sitting position by the Riva-Rocci method after at least 5 min of rest on three consecutive days before and 6-8 days after surgery. The mean of three respective measurements was calculated.

The following methods were used in the laboratory tests: seNa and seK: flame photometry (Efox 5053, Eppendorf, Netheler Hinz GmbH, Hamburg, Germany), normal range: seNa: 137-147 mmol/l, seK: 3.5$5.5 \mathrm{mmol} / \mathrm{l}$; seCa: colorimetry, (Randox, Crumlin, UK), normal range: $2.02-2.60 \mathrm{mmol} / \mathrm{l}$; seP: colorimetry (Randox), normal range: $0.87-1.45 \mathrm{mmol} / \mathrm{l}$; seMg: colorimetry (Diagnosticum, Budapest, Hungary), normal range: 0.65-1.03 mmol/l; PTH: IRMA (Bio-Rad, Hercules, CA, USA), normal range: $1.0-6.5 \mathrm{pmol} / \mathrm{l}$; aldosterone: RIA (Serono, Milan, Italy), normal range, basal: $12-150 \mathrm{pg} / \mathrm{ml}$, stimulated: $70-350 \mathrm{pg} / \mathrm{ml}$; PRA: RIA (DuPont, Boston, MA, USA), normal range, basal: 0.2$2.8 \mathrm{ng} / \mathrm{ml} / \mathrm{h}$, stimulated: $1.5-5.7 \mathrm{ng} / \mathrm{ml} / \mathrm{h}$; glucose: glucose oxidase-peroxidase-phenol-amino-antipyrine (GODPOD-PAP) method, Epos 5060 equipment (Eppendorf, Netheler Hinz $\mathrm{GmbH}$ ), normal range: 3.3-5.6 mmol/l; insulin: RIA (Izotóp Intézet, Budapest, Hungary), normal range: $5-25 \mathrm{mIU} / \mathrm{l}$.

Statistical evaluation of the results was performed by using the Statgraphics 5.1 program package. Because of the low case number, rank-statistical methods were applied, i.e. Wilcoxon's signed rank test and Spearman's correlation, except for blood pressure, where Student's paired $t$-test was used. In the case of blood pressure values are given as the mean \pm S.D., whereas in the rest of the cases the median and quartiles are given. $P<0.05$ was considered as the significance limit.

The study was approved by the Ethical Committee of the Haynal Imre University of Health Sciences.

\section{Results}

As expected, the previously pathologically high serum calcium, magnesium and PTH levels decreased significantly, while serum phosphorus values increased one week after parathyroidectomy. These changes can be attributed to the successful tumor removal. SeNa and seK did not change (Table 1). Basal and stimulated renin levels as well as the stimulated aldosterone levels were elevated prior to surgery. These findings indicate a secondary hyperaldosteronism. After surgery, both the basal and the stimulated PRA and ALD values decreased significantly; they shifted from the pathological to the normal range. Detailed results are given in Table 2. The changes in basal PRA values correlated significantly with the changes in PTH levels $(n=16$, $r=0.5442, P<0.05)$ but did not correlate with the changes in calcium or phosphorus concentrations 
Table 1 Serum ion concentrations (mmol/l) in patients with PHPT before and after removal of the parathyroid tumor $(n=16)$.

\begin{tabular}{|c|c|c|c|c|c|c|c|}
\hline \multirow[b]{3}{*}{ Parameter } & \multicolumn{3}{|c|}{ Before surgery } & \multicolumn{3}{|c|}{ After surgery } & \multirow[b]{3}{*}{$P$ value* } \\
\hline & \multicolumn{3}{|c|}{ (percentile) } & \multicolumn{3}{|c|}{ (percentile) } & \\
\hline & 25 & 50 & 75 & 25 & 50 & 75 & \\
\hline $\mathrm{seCa}$ & 2.77 & 2.85 & 3.11 & 1.92 & 1.98 & 2.18 & $<0.001$ \\
\hline seMg & 0.80 & 0.88 & 0.94 & 0.64 & 0.68 & 0.77 & 0.0031 \\
\hline seP & 0.57 & 0.68 & 0.84 & 0.64 & 0.87 & 1.08 & 0.0171 \\
\hline seNa & 142.0 & 142.5 & 143.0 & 142.0 & 144.0 & 145.0 & NS \\
\hline sek & 4.0 & 4.3 & 4.5 & 3.7 & 4.3 & 4.6 & NS \\
\hline
\end{tabular}

* Wilcoxon's signed rank test.

NS, not significant.

( $n=16, r=0.1805$, not significant (NS) and $n=16$, $r=0.2168$, NS respectively). There were no significant correlations between the changes in ALD (dALD) and PTH $(\mathrm{dPTH})$ values or calcium (dCa) levels (dPTHdALD: $n=16, r=0.4148$, NS; dCa-dALD: $n=16$, $r=0.2883$, NS).

Following surgery, both the basal insulin levels and the AUC values obtained during the OGTT decreased significantly compared with the preoperative values (Table 3). However, both the preoperative and postoperative values remained within the normal range. Blood sugar values did not change significantly (Table 4). No statistically significant correlation was demonstrated between the changes in insulin levels (dins) and the PTH or ion concentrations (dins basal $^{-}$ dPTH: $n=12, r=0.3570$, NS; dins basal $-\mathrm{dCa}: n=12$, $r=0.3710, \mathrm{NS}$; dins basal $\mathrm{dP}: n=12, r=0.3634$, NS; dins $_{\mathrm{AUC}}-\mathrm{dPTH}: n=12, r=0.1568, \mathrm{NS}$; dins ${ }_{\mathrm{AUC}}-\mathrm{dCa}$ : $n=12, r=0.1257$, NS; dins ${ }_{\mathrm{AUC}}-\mathrm{dP}: n=12, r=0 \cdot 2629$, NS).

Regarding the blood pressure, the systolic values decreased only slightly, but the change was still statistically significant $(P=0.038)$; the diastolic values remained unaffected by surgery (preoperative mean: $123.3 \pm 13.0 / 80 \pm 8.6$, postoperative mean: $116.7 \pm$ $13.5 / 77.3 \pm 8.8 \mathrm{mmHg})$.

\section{Discussion}

Our findings show a hyperactivity of the reninaldosterone system even in normotensive PHPT patients corresponding to a secondary hyperaldosteronism. Our data are in good agreement with those of Sotornik et al. (7) and Gennari et al. (9) but with some additional new findings. First, we have demonstrated a pathologically increased sensitivity of the renin-aldosterone system to

Table 2 Hormone values (PTH, PRA and ALD) in patients with PHPT before and after the removal of the parathyroid tumor $(n=16)$.

\begin{tabular}{|c|c|c|c|c|c|c|c|}
\hline \multirow[b]{3}{*}{ Parameter } & \multicolumn{3}{|c|}{ Before surgery } & \multicolumn{3}{|c|}{ After surgery } & \multirow[b]{3}{*}{$P$ value ${ }^{*}$} \\
\hline & \multicolumn{3}{|c|}{ (percentile) } & \multicolumn{3}{|c|}{ (percentile) } & \\
\hline & 25 & 50 & 75 & 25 & 50 & 75 & \\
\hline PTH (pmol/l) & 11.0 & 20.6 & 65.5 & 2.0 & 3.5 & 7.1 & $<0.001$ \\
\hline $\mathrm{PRA}_{\text {basal }}(\mathrm{ng} / \mathrm{ml} / \mathrm{h})$ & 0.71 & 1.79 & 5.10 & 0.40 & 0.70 & 0.87 & 0.0049 \\
\hline $\mathrm{PRA}_{\text {stimulated }}(\mathrm{ng} / \mathrm{ml} / \mathrm{h})$ & 5.27 & 7.76 & 13.75 & 1.00 & 1.90 & 4.83 & 0.0031 \\
\hline$A_{L D}$ basal $(\mathrm{pg} / \mathrm{ml})$ & 86.0 & 111.5 & 179.0 & 52.0 & 73.0 & 87.0 & 0.0258 \\
\hline $\operatorname{ALD}_{\text {stimulated }}(\mathrm{pg} / \mathrm{ml})$ & 344.5 & 392.5 & 619.0 & 163.0 & 236.0 & 323.0 & 0.0157 \\
\hline
\end{tabular}

*Wilcoxon's signed rank test.

Table 3 Basal and stimulated (OGTT) insulin values in patients with PHPT before and after the removal of the parathyroid tumor $(n=12)$.

\begin{tabular}{|c|c|c|c|c|c|c|c|}
\hline \multirow[b]{3}{*}{ Parameter } & \multicolumn{3}{|c|}{ Before surgery } & \multicolumn{3}{|c|}{ After surgery } & \multirow[b]{3}{*}{$P$ value } \\
\hline & \multicolumn{3}{|c|}{ (percentile) } & \multicolumn{3}{|c|}{ (percentile) } & \\
\hline & 25 & 50 & 75 & 25 & 50 & 75 & \\
\hline Insulin $_{\text {fasting }}(\mathrm{mlU} / \mathrm{l})$ & 4.35 & 10.2 & 16.7 & 4.7 & 5.0 & 10.7 & 0.0218 \\
\hline Insulin ${ }_{\mathrm{AUC}}\left(\mathrm{mlU} / \mathrm{I}^{*} \mathrm{~min}\right)$ & 3839 & 5555 & 8114 & 2484 & 3296 & 5538 & 0.0218 \\
\hline
\end{tabular}

*Wilcoxon's signed rank test. 
Table 4 Basal and stimulated (OGTT) glucose values in patients with PHPT before and after the removal of the parathyroid tumor $(n=12)$.

\begin{tabular}{|c|c|c|c|c|c|c|c|}
\hline \multirow[b]{3}{*}{ Parameter } & \multicolumn{3}{|c|}{ Before surgery } & \multicolumn{3}{|c|}{ After surgery } & \multirow[b]{3}{*}{$P$ value $^{\star}$} \\
\hline & \multicolumn{3}{|c|}{ (percentile) } & \multicolumn{3}{|c|}{ (percentile) } & \\
\hline & 25 & 50 & 75 & 25 & 50 & 75 & \\
\hline $\operatorname{Glucose}_{\text {fasting }}(\mathrm{mmol} / \mathrm{l})$ & 3.8 & 4.2 & 4.4 & 3.9 & 4.1 & 4.3 & NS \\
\hline Glucose $_{\text {AUC }}\left(\mathrm{mmol} / /^{*} \mathrm{~min}\right)$ & 750.0 & 817.5 & 892.5 & 669.8 & 749.3 & 820.5 & NS \\
\hline
\end{tabular}

*Wilcoxon's signed rank test.

stimulation by volume depletion and orthostasis. This has not been investigated before. Secondly, in our study, the dependence of the hyperactivity of the reninaldosterone system on the parathyroid status was clearly demonstrated by normalization of the PRA and ALD values following surgery. Thirdly, the correlation of the PTH and basal PRA values indicated that PTH itself may be a stimulating factor for PRA in PHPT. Although the lack of correlation between seCa and PRA values in this small study group does not exclude the effect of hypercalcemia on plasma renin activity, in the light of the results of experimental studies, the importance of elevated levels of circulating PTH in increasing renin secretion seems to be proved. In essence, our data serve as a clinical confirmation of a number of previous experiments $(1,19,20)$.

Several authors have reported on alterations of insulin secretion in hypercalcemic, hypophosphatemic conditions (PHPT, secondary hyperparathyroidism, or in cases of experimental hypercalcemia or phosphate depletion) (reviewed in (13)). Some authors have observed a reduced insulin secretion in cases of phosphate depletion (21) and secondary hyperparathyroidism accompanied by renal failure $(22,23)$. Moreover, an increased insulin release causing hypoglycemia following parathyroidectomy was observed in a hemodialysis patient (24). The majority of authors, however, observed hyperinsulinemia or insulin resistance in PHPT (15-17), in secondary hyperparathyroidism $(15,25,26)$ or in hyperparathyroidism associated with multiple endocrine neoplasia syndrome type 1 (18). It is believed that hyperinsulinism and insulin resistance play a role in the pathogenesis of arterial hypertension. The consequences of hyperinsulinemia are increased sympathetic activity and decreased adrenal medullar activity; these changes may affect blood pressure, triglyceride and high density lipoprotein-cholesterol levels leading to an increased cardiovascular risk (10). The background of this pathological process is still unclear; in addition to sodium retention, increased intracellular free calcium levels, and reduced magnesium and ATP concentrations $(12,27)$ may also play a role in its pathomechanism. Genetic predisposition is also probable (28). Factors that might be related to hypertension in hyperparathyroidism are the parathyroid hypertensive factor (29), or the islet amyloid polypeptide, also called amylin (30).
Our study on insulin secretion in PHPT is different from previous reports since only normotensive, euglycemic patients were selected in order to have a more homogenous patient group, and the functional state of the renin-aldosterone system and insulin secretion were investigated concommittantly. In this patient group, a significant reduction was observed in both the basal and stimulated insulin values following the removal of the parathyroid tumors causing PHPT. The values remained within the normal range in both the pre- and postoperative period and no significant changes in the blood glucose levels were observed. There was, however, no significant correlation between insulin values and the other examined variables.

\section{Acknowledgement}

The authors are grateful to András Paksy for his valuable assistance in the statistical procedures.

\section{References}

1 Helwig J-J, Musso M-J, Judes C \& Nickols GA. Parathyroid hormone and calcium: interactions in the control of renin secretion in the isolated nonfiltering rat kidney. Endocrinology $19911291233-1242$.

2 Valvo E, Bedogna V, Gammaro L, Casagrande P, Ortalda V \& Maschio G. Systemic hemodynamic pattern in primary hyperparathyroidism and its changes after parathyroidectomy. Mineral and Electrolyte Metabolism 199117 147-152.

3 Salahudeen AK, Thomas TH, Sellars L, Tapster S, Keavey P, Farndon JR et al. Hypertension and renal dysfunction in primary hyperparathyroidism: effect of parathyroidectomy. Clinical Science 198976 289-296.

4 Fallo F, Rocco S, Pagotto U, Zangari M, Luisetto G \& Mantero F. Aldosterone and pressor responses to angiotensin II in primary hyperparathyroidism. Journal of Hypertension 19897 (Suppl 6) 192-193.

5 Takata Y, Takishita S, Koga T, Nakao Z, Okamura K, Yao T et al. Hypotensive effects of nifedipine in patients with primary hyperparathyroidism: case reports. Angiology $1989401079-$ 1082.

6 Rodriguez-Portales JA \& Fardella C. Primary hyperparathyroidism and hypertension: persistently abnormal pressor sensitivity in normotensive patients after surgical cure. Journal of Endocrinological Investigation 199417 307-311.

7 Sotornik I, Stribrna J. Hronova J, Kocandrle V, Janata V, Taborsky $\mathrm{P}$ et al. Changes in plasma renin and aldosterone after parathyroidectomy in patients with hyperparathyroidism. Casopis Lekaru Ceskych 1993132 45-49.

8 Nami R, Martinelli M, Zacchei F, Panza F, Pavese G \& Gennari C. Serum ionized calcium, parathormone and plasma renin activity 
in essential arterial hypertension. Minerva Cardioangiologica 1989 37 91-98.

9 Gennari C, Nami R \& Gonelli S. Hypertension and primary hyperparathyroidism: the role of adrenergic and reninangiotensin-aldosterone system. Mineral and Electrolyte Metabolism $19952177-81$.

10 Reaven GM, Lithell H \& Landsberg L. Hypertension and associated metabolic abnormalities - the role of insulin resistance and sympathoadrenal system. New England Journal of Medicine 1996 334 374-381.

11 Landsberg L. Insulin sensitivity in the pathogenesis of hypertension and hypertensive complications. Clinical and Experimental Hypertension 199618 337-346.

12 Weidmann P, Muller-Wieland D, de Courten M \& Krone W. Insulin resistance and arterial hypertension. Herz $19952016-32$.

13 Kautzky-Willer A, Niederle B, Schernthaner G \& Prager R. Diabetes mellitus and carbohydrate metabolism in primary hyperparathyroidism. Wiener Klinische Wochenschrift 1993105 158-162.

14 Taylor WH. The prevalence of diabetes mellitus in patients with primary hyperparathyroidism and their relatives. Diabetic Medicine 19918 683-687.

15 Yamagishi K. Pancreatic exocrine and endocrine functions stimulated with secretin and thyrotropin-releasing hormone in patients with hyperparathyroidism. Nippon Geka Gakkai Zasshi $199293494-504$.

16 Kumar S, Olukoga AO, Gordon C, Mawer EB, France M, Hosker JP et al. Impaired glucose tolerance and insulin insensitivity in primary hyperparathyroidism. Clinical Endocrinology 199440 47-53.

17 Kautzky-Willer A, Pacini G, Niederle B, Schernthaner G \& Prager R. Insulin secretion, insulin sensitivity and hepatic insulin extraction in primary hyperparathyroidism before and after surgery. Clinical Endocrinology 199237 147-155.

18 Furuto-Kato S, Shimatsu A, Kuzuya H, Matsuda K. Nakao K \& Imura H. Insulin sensitivity and glycemic control before and after parathyroidectomy in a diabetic patient with familial multiple endocrine neoplasia type 1. Endocrine Journal 199441 731-735.

19 Grant FD, Mandel SJ, Brown EM, Williams GH \& Seely EW. Interrelationships between the renin-angiotensin-aldosterone and calcium homeostatic systems. Journal of Clinical Endocrinology and Metabolism 199275 988-992.
20 Olgaard K, Lewin E, Bro S, Daugaard H, Egfjord M \& Pless V. Enhancement of the stimulatory effect of calcium on aldosterone secretion by parathyroid hormone. Mineral and Electrolyte Metabolism 199420 309-314.

21 Levi E, Fadda GZ, Ozbasli C \& Massry SG. Evolution of metabolic and functional derangements of pancreatic islets in phosphate depletion. Endocrinology 1992131 2182-2188.

22 Ritz E, Stefanski A \& Rambausek M. The role of the parathyroid glands in the uremic syndrome. American Journal of Kidney Diseases $199526808-813$.

23 Hajjar SM, Fadda GZ, Thanakitcharu P, Smogorzewski M \& Massry SG. Reduced activity of $\mathrm{Na}(+)-\mathrm{K}+$ ATPase of pancreatic islets in chronic renal failure: role of secondary hyperparathyroidism. Journal of the American Society of Nephrology 19922 1355-1359.

24 Nadkarni M, Berns JS, Rudnick MR \& Cohen RM. Hypoglycemia with hyperinsulinemia in a chronic hemodialysis patient following parathyroidectomy. Nephron 199260 100-103.

25 Kautzky-Willer A, Pacini G, Barnas U, Ludvik B, Streli C, Graf H et al. Intravenous calcitriol normalizes insulin sensitivity in uremic patients. Kidney International 199547 200-206.

26 Spustova V, Stefikova K, Hustavova L \& Dzurik R. Insulin resistance in kidney diseases. Vnitrini Lekarstvi 199541 129135.

27 Resnick LM. Cellular calcium and magnesium metabolism in the pathophysiology and treatment of hypertension and related metabolic disorders. American Journal of Medicine 199293 (Suppl 2/a) 11-20.

28 Weidmann P, Bohlen L \& de Courten M. Insulin resistance and hyperinsulinemia in hypertension. Journal of Hypertension 1995 13 (Suppl) 65-72.

29 Ho MS, Lewanczuk RZ, Teh BH, Lee SC \& Pang PK. Parathyroid hypertensive factor and non-insulin-dependent diabetes mellitus. Journal of Cardiovascular Pharmacology 199423 (Suppl 2) 31-34.

30 Valdemarsson S, Leckström A, Westermark P \& Bergenfelz A. Increased plasma levels of islet amyloid polypeptide in patients with primary hyperparathyroidism. European Journal of Endocrinology $1996134320-325$.

Received 17 July 1997

Accepted 9 February 1998 